\title{
Chronic conditions and the challenges for knowledge production in health
}

\author{
Regina Aparecida Garcia de Lima
}

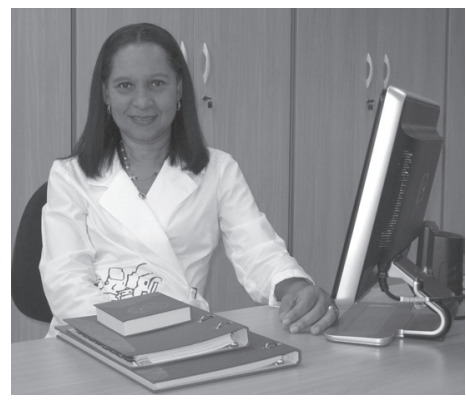

Care delivery to noncommunicable diseases like cardiovascular conditions, diabetes mellitus, cancer, chronic obstructive pulmonary disease, represents a challenge for health systems in developed or developing countries. In $2008,63 \%$ of global mortality and $45.9 \%$ of the global disease burden were attributed to these conditions. In low and medium-income countries, mortality rates due to noncommunicable chronic illnesses reach $80 \%{ }^{(1)}$.

Acknowledging the opportunity to improve these indicators, the World Health Organization launched the project Innovative Care for Chronic Conditions and proposed a chronic condition management plan to health systems, aiming for problem solving as opposed to mere treatment of symptoms when they emerge ${ }^{(2)}$.

This finding is based on research, showing that most people affected by these problems do not receive appropriate care; when considering care on the whole, approximately half of the cases are diagnosed and receive medical care. Therefore, the Pan American Health Organization(3) elaborated a document in which it presents the Chronic Care Model. In that model, primary health care plays a central role, but should be complemented by the specialized and intensive care centers, such as specialized care clinics, hospitals and rehabilitation centers.

With a view to the success and qualification of care based on the Chronic Care Model, the care focus should be centered on patients and their families; on the elaboration of multi-sector policies for the management of chronic conditions, including universal access to the best practices; on the creation of a clinical information system for the monitoring and assessment of quality improvement strategies; on the operation of systematic support for patients' selfmanagement; on the orientation of care towards disease prevention and health promotion, with community participation; on the creation of care networks led by primary health care; on the reorientation of health services through the creation of a chronic care culture, including evidence-based proactive care and the constitution of multidisciplinary health teams, guaranteeing continuing education for the management of chronic conditions.

On the other hand, if we truly want to face the challenges, these problems should be investigated in the field of chronic illnesses, in different contexts, such as the clinical, hospital, home care, community and public policies. A wide range of research methods can be applied to these research problems, such as integrative and systematic review; clinical trials; evaluation, methodological and epidemiological, phenomenological and ethnographic studies. Possible participants include patients and their relatives, informal caregivers, health service managers and health professionals. Countless research instruments can be used, such as laboratory tests; questionnaires and scales, in-depth interviews and observation. That is so because this particular research themes moves from the cellular to the community level, from the individual to the family, from the public to the private, from the particular to the general, from the clinical to the epidemiological, from the diagnosis to survival or death.

Hence, there is no unique formula to develop an efficient and effective health system for the control of chronic conditions. Other projects, protocols and recommendations can be formulated and, in all of these situations, research plays a fundamental role as, based on this activity, strong evidence will contribute to decision-making on the best practices for the control of chronic illnesses. 


\section{References}

1. World Health Organization. Global status report on noncommunicable diseases. Geneva: WHO; 2010.

2. Organização Mundial da Saúde. Cuidados inovadores para as condições crônicas: componentes estruturais de ação: Relatório Mundial. Brasília; 2013.

3. Organización Panamericana de la Salud. Cuidados innovadores para las condiciones crónicas: Organización y prestación de atención de alta calidad a las enfermedades crónicas no transmisibles en las Américas. Washington, DC: OPS; 2013.

Regina Aparecida Garcia de Lima is Scientific Editor of the Revista Latino-Americana de Enfermagem and Full Professor of the Escola de Enfermagem de Ribeirão Preto, Universidade de São Paulo, WHO Collaborating Centre for Nursing Research Development, Ribeirão Preto, SP, Brazil, e-mail: limare@eerp.usp.br. 